\title{
Obstructive Sleep Apnea, Prevalence, Etiology \& Role of Dentist \& Oral Appliances in Treatment: Review Article
}

\author{
Mohammad Jaradat, Ahmad Rahhal* \\ Department of Orthodontics, Faculty of Dentistry, Arab American University, Jenin, West-Bank, Palestine \\ Email: "plorahhal@hotmail.com
}

Received 30 May 2015; accepted 14 July 2015; published 17 July 2015

Copyright (C) 2015 by authors and Scientific Research Publishing Inc.

This work is licensed under the Creative Commons Attribution International License (CC BY).

http://creativecommons.org/licenses/by/4.0/

(c) (i)

Open Access

\section{Abstract}

Objective: The aim of this article is to provide a detailed description for obstructive sleep apnea regarding its signs and symptoms, the way it is diagnosed, the risk factors, management, the role of dentists and oral appliances in treatment and consequences of untreated condition. Material and Method: Electronic searching was done in PubMed, Medline, EMBASE and CENTRAL databases. Inclusion criteria were: dental, oral and maxillofacial oriented articles. Exclusion criteria: cardiac, obesity and non dental oriented articles were excluded. Result: 59 articles meet the criteria. Conclusion: Obstructive sleep apnea (OSA) is a potentially life threatening disorder characterized by repeated collapse of the upper airway during sleep, with periodic cessation of breathing for more than ten seconds. The frequency of obstructive sleep apnea has been found to increase with age; ranging from two percent among children to two and half percent - six percent among adolescents. Overnight polysomnographic test at specialized sleep clinics remains the gold standard for diagnosing obstructive sleep apnea disorder. Management of this condition can be performed via surgical and non surgical methods. Continuous positive airway pressure represents the first line of treatment for most patients with obstructive sleep apnea.

\section{Keywords}

Obstructive Sleep Apnea, Role of Oral Appliances in Treatment, Continuous Positive Airway Pressure, Maxillomandibular Advancement Surgery

\section{Introduction \& Definition}

Sleep ranks among the three most important considerations in maintaining good health. So the presence of

\footnotetext{
${ }^{*}$ Corresponding author.
}

How to cite this paper: Jaradat, M. and Rahhal, A. (2015) Obstructive Sleep Apnea, Prevalence, Etiology \& Role of Dentist \& Oral Appliances in Treatment: Review Article. Open Journal of Stomatology, 5, 187-201. 
fragmented sleep has a negative effect on the patients' overall health.

In order to prepare this article an electronic searching was done in PubMed, Medline, EMBASE and CENTRAL databases. Inclusion criteria were: dental, oral and maxillofacial oriented articles.

Exclusion criteria: cardiac, obesity and non dental oriented articles were excluded. In order to do the search words like: obstructive sleep apnea, dentist, orthodontist and oral appliance were used. In the result 59 articles meet the criteria.

Obstructive sleep apnea (OSA) is a potentially life threatening disorder characterized by repeated collapse of the upper airway during sleep, with periodic cessation of breathing (for more than 10 seconds). These events usually result in fragmented sleep [1] [2].

The frequency of obstructive sleep apnea has been found to increase with age, ranging from $2 \%$ among children [3] [4] to $2.5 \%$ - 6\% among adolescents [5]. Obstructive sleep apnea in children typically appears between the ages of 2 and 7 years [2]. It has been found that obstructive sleep apnea is found in 2 to 4 percent of the adult population between the ages of 30 to 60 years [6]. Other studies reveal that obstructive sleep apnea affects approximately $0.3 \%$ - $4 \%$ of the middle aged population [7] [8].

It is documented that obstructive sleep apnea has a great negative effect on the patient's life. These negative effects range from fragmented sleep, behavior problems, and reduced academic performance to much more severe problems represented in the form of cardiopulmonary defects [2].

Ye L., Pien G.W. and Weaver T.E. (2009), reported that obstructive sleep apnea was more common in males rather than females [9]. Similar finding was found by Goodwin and others [2]. There is a proportional relationship between the frequency of obstructive sleep apnea and the increase in age [10] [11].

So it is of great importance to know how to diagnose and treat such a life threatening condition.

\section{Pathogenesis}

Obstructive sleep apnea is produced via an Occlusion of the oropharyngeal airway which produces a progressive asphyxia until there is a brief arousal from sleep, whereupon airway patency is restored and airflow returns back [12].

It should be known that during wakefulness, the activity of the upper airway muscle is greater than normal which helps to compensate for airway narrowing and high airway resistance [2] [12].

Structural abnormalities that predispose the patient to obstructive sleep apnea are:

- Reduction in mandibular length appears to be the most common and, probably, most important skeletal abnormality predisposing to OSA [12].

- Anatomic disturbances such as tonsillar hypertrophy, retrognathia of either jaw and the presence of large tongue (Macroglosia) [2] [12].

- Obesity may contribute to reduction in upper airway size by increasing the amount of fat deposited in the soft tissues of the pharynx or by compressing the pharynx by superficial fat masses in the neck [2].

\section{Diagnosis}

The gold standard for diagnosing Obstructive Sleep Apnea is an overnight test called polysomnographic test. In this test the main parameters used for diagnosis of Obstructive Sleep Apnea are the Apnea hypopnea index (AHI, defined as the number of breathing obstructions per hour) along with oxygen desaturation levels. It must be noted that the polysomnographic diagnostic criteria for OSA in children are somewhat different from those in adults. Among children, an AHI $>1$ and oxygen desaturation $\geq 4 \%$ are indicators of mild OSA [8]-[10]. In comparison, an AHI of 5 (or sometimes 10) among adults generally indicates mild OSA [2].

Apnea is defined as a cessation of airflow for greater than 10 seconds with continued chest and abdominal effort, while hypopnea is defined as a decrease in amount of air breathed (by 50\%) with a desaturation of at least 3\% [2].

The following figure shows the types of sleep apnea (central, obstructive and mixed): (Figure 1).

- Central sleep apnea is the condition in which the neural drive to all respiratory muscles is abolished resulting in apnea [1].

- Obstructive sleep apnea is the condition in which there is an occlusion of the oropharyngeal airway for more than ten seconds during sleep [1].

Obstructive Sleep Apnea severity is classified on the basis of the patient's AHI (Apnea hypopnea index) score, 
into three categories mentioned in Table 1 [13]. The normal apnea hypopnea index score is less than 5 events per hour [13].

Other factors that also influence the severity of OSA include: quality of life and the level of daytime sleepiness [14]. Regarding oxygen saturation: the normal blood oxygen level should be above $90 \%$.

In the cases of obstructive sleep apnea, the severity of the problem can be divided into the following: Table 2 [3].

Pharyngeal Wall Floppiness is a non invasive and reproducible technique which may used as a tool in Obstructive Sleep Apnea assessment because the Obstructive Sleep Apnea population had greater pharyngeal wall floppiness compared to healthy subjects [15].

Risk factors: include a family history of snoring or OSA, the presence of a massive uvula, physical abnormalities, cerebral palsy, muscular dystrophy, Down's syndrome, sickle-cell disease, head and neck masses, vocal cord paralysis, sedative use, smoking, hypothyroidism, mouth breathing and any condition that may lead to a narrowing of the upper airway.

An important general risk factor for OSA is obesity. According to Tauman and Gozal, recent increasing rates of childhood obesity have led to an increase in the prevalence of OSA among children, as the condition has been shown to be positively correlated with body mass index [2].

Obesity is intimately associated with OSA; the majority of obese patients have some degree of OSA, and the majority of patients with OSA are obese [16] [17]. Increasing body mass index, neck circumference and waistto-hip ratio are all associated with increased prevalence of OSA. So a body mass index (BMI) over 25 and/or a neck size over 16 inches puts an individual at risk for sleep apnea [18].

Another important risk factor is adenotonsilar hypertrophy; which refers to the condition where the adenotonsillar tissue increases in size and so occupies a larger area in the wall of the nasopharynx [2].

Diaphragmatic Excursions

Figure 1. Types of sleep apnea [1].

Table 1. Apnea hypopnea index score.

\begin{tabular}{cc}
\hline AHI score & Description \\
\hline Mild & AHI score between 5 and 15 events per hour \\
Moderate & AHI score between 15 and 30 events per hour \\
Severe & AHI score greater than 30 events per hour \\
\hline
\end{tabular}

Apnea hypopnea index score [13].

Table 2. Severity of obstructive sleep apnea.

\begin{tabular}{cc}
\hline OSA severity & Description \\
\hline Mild & $85 \%-90 \%$ oxygen saturation \\
Moderate & $80 \%-84 \%$ oxygen saturation \\
Severe & Below $80 \%$ oxygen saturation \\
\hline
\end{tabular}

Severity of obstructive sleep apnea [3]. 
The following figures represent an enlargement in the adeno-tonsillar tissue (Figure 2) and a massive uvula [2].

Cases in which the hyoid bone is at a distance greater than $20 \mathrm{~mm}$ below the border of the mandible are considered a risk factor for Obstructive Sleep Apnea [3] (Figure 3).

Signs and symptoms: the nocturnal signs and symptoms include the following:

- Drooling,

- Xerostomia,

- Sleep restlessness,

- Witnessed apneas,

- Choking or gasping and diaphoresis [14].

\section{The Daytime Signs and Symptoms}

These include: Excessive sleepiness, Xerostomia, Morning headaches, Nonrestorative sleep, Gastroesophageal reflux disease, Impaired concentration, Depression, Decreased libido, Impotence and Irritability [14].

Symptoms of Obstructive sleep apnea among children include snoring, pauses in breathing while asleep, restless sleep, bizarre sleeping positions (Figure 4), paradoxical chest movements, cyanosis, bedwetting, hyperactivity, stunted growth and disruptive behavior in school, poor concentration, nightmares, night terrors, headaches, Chronic runny noses And frequent upper airway infections [18].
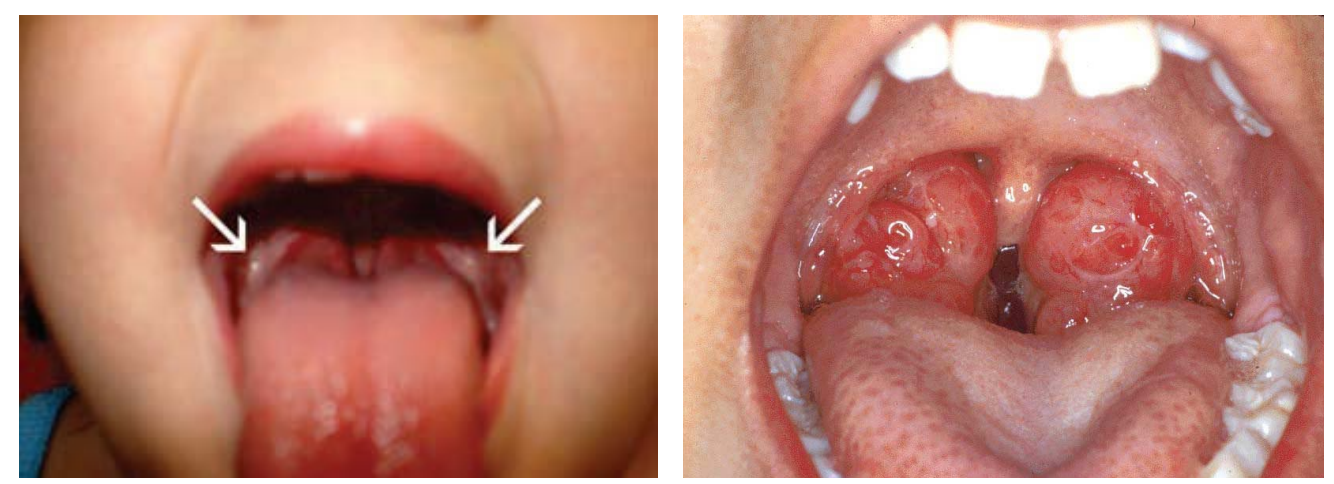

Figure 2. Adenotonsillar hypertrophy [2].

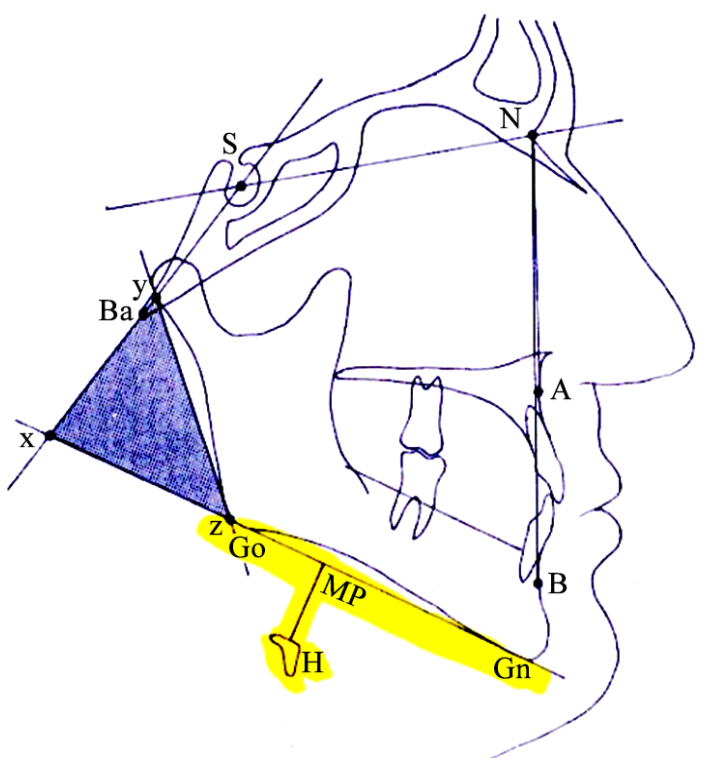

Figure 3. Hyoid bone greater than $20 \mathrm{~mm}$ from the mandible [3]. 


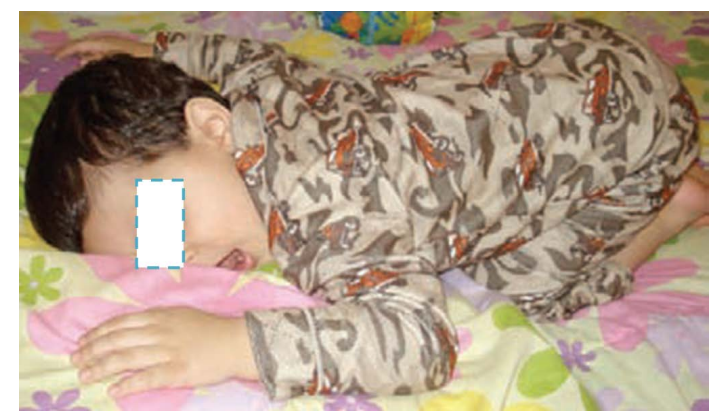

Figure 4. Characteristic sleeping position of a child with sleep apnea [18].

\subsection{Orofacial Findings}

The most common orofacial characteristics of obstructive sleep apnea patients include a retrognathic mandible, narrow palate, large neck circumference, long soft palate (which leads to dentists' being unable to visualize the entire length of the uvula when the patient's mouth is open wide), tonsillar hypertrophy, nasal septal deviation and relative macroglossia. It should be known that the population with OSA is a heterogeneous group, and patients with OSA may not have all of these physical features [14].

Tangugsorn V. et al. (1995) found in their study that most patients with obstructive sleep apnea have maxillary and mandibular retrognathia [19].

The literature provides abundant evidence that the antero-posterior position of the mandible in Obstructive Sleep Apnea patients is a retrognathic one [19].

Enache A.M. et al. (2010) found that Romanian patients with OSA have a retrognathic antero-posterior facial pattern, the mandible and the maxilla having a posterior position with respect to the cranial base. They also found that the vertical skeletal pattern is normal with the predominance of the posterior rotation of the mandible. And they found that the Use of ANB as a linear predictor for AHI may indicate OSA predisposition since a statistically significant positive correlation between Apnea Hypopnea Index and ANB angle had been found [20].

Recently Dotan Y. et al. (2015) confirmed in their study that the intense genioglossus muscle activation fails to prevent pharyngeal obstruction during sleep among obstructive sleep apnea patients [21].

\subsection{Consequences of Untreated OSA in Children}

Due to the acute increases in blood pressure and arrhythmias associated with apneas and intermittent hypoxia the strain on the cardiovascular system has been found to be increased in these patients [22] [23].

This was also supported by McCrillis et al. (2009); they mentioned in their study that untreated cases of obstructive sleep apnea may put the patient at an increased chance of developing cardiovascular problems such as: systemic hypertension, coronary heart disease, cardiac arrhythmias, sudden nocturnal death, stroke, or pulmonary hypertension [24].

Ciccone et al. (2014) Concluded that the repetitive episodes of hypoxia/reoxygenation associated with transient cessation of breath during sleep, and sleep fragmentation/deprivation in obstructive sleep apnea patients initiates a systemic inflammation which is characterized by an increase in the level of certain inflammatory markers such as hsCRP, IL-6, TNF- $\alpha$, and PTX-3. The increase in the level of these inflammatory markers significantly increases the carotid media thickness in OSA patients which makes these patients much more prone to atherosclerosis compared to the un affected people [25].

Those who suffer from OSA may snort awake, thus experiencing fragmented sleep [2]. Untreated obstructive sleep apnea cases may lead to Social and behavioral effects such as drowsy driving/accidents, decreased work performance or Poor quality of life [24].

Among children (particularly) Obstructive Sleep Apnea can lead to severe developmental problems including failure to thrive, enuresis, attention deficit disorder, behavior problems, decreased academic performance and cardiopulmonary disease [26]. Several studies have shown that children with Obstructive Sleep Apnea are more aggressive, have higher rates of inattention, are more moody and have impaired visual perception and working memory [27] [28]. 


\subsection{Management}

Obstructive sleep apnea is a condition that can be managed via surgical or non surgical methods. Treatment modality depends on the following:

1) severity of the patient's symptoms.

2) results of the polysomnogram.

3) and impact on co-morbid diseases such as heart failure.

The surgical methods include: adenotonsillectomy, mandibular advancement, maxilla-mandibular advancement and uvulopalatopharyngoplasty procedures.

Nonsurgical methods for the treatment of obstructive sleep apnea include: continuous positive airway pressure, diet, medications and oral appliances.

\subsubsection{Adenotensilectomy}

Because adenotonsillar hypertrophy is a significant contributing factor to obstructive sleep apnea among children, for many, removal of the tonsils is the ultimate treatment of their OSA. In fact, for up to $80 \%$ of children diagnosed with OSA management via adenotonsillectomy was found to be an effective treatment [29].

Chan et al. (2004) and others reported that adenotonsillectomy had a positive impact represented in decreasing snoring, obstructive sleep apnea, weight problems, enuresis and behavior problems in children with Obstructive sleep apnea [26].

Elsherif and Kareemullah (1999) expressed the strong view that all children with large tonsils should consider adenotonsillectomy as well as a polysomnography recording [30].

Another study found that the performance of adenotonsillectomy significantly reduced health care utilization by children with Obstructive Sleep Apnea [31].

Linder-Aronson et al. (1986); Woodside et al. (1991) found that after the performance of adenoidectomy and facilitation of nasal breathing, mandibular growth and closure of the mandibular plane angle(but not the maxillary plane angle,) was accelerated, however, with a large variation in response [32].

Kerr et al. (1989) made a comparison between adenoidectomy patients and a control group regarding the amounts of growth of mandibular (ramus and condylar process). The results revealed that growth was greater in the adenoidectomy group than that in the control group [32].

\subsubsection{Maxillomandibular Advancement Surgery: (Figure 5)}

Claudio Vicini et al. (2008) found that that Maxillo-mandibular advancement improves Apnea Hypopnea Index and Epworth Sleepiness Scale significantly when compared to Autotitrating Positive Airway Pressure, and for this reason, it could be considered an effective alternative option for patients with severe Obstructive Sleep Apnea Hypopnea Syndrome. Moreover, the improvement obtained in the Maxillo-Mandibular Advancement group is comparable with the improvement obtained in the autotitrating Positive airway Pressure group [33].

Maurer J.T. (2010) has mentioned that maxillomandibular advancement is as effective as Continuous Positive Airway Pressure in severe cases of Obstructive Sleep Apnea. He mentioned also that tonsillectomy and maxillomandibular advancement may be provided as a first-line treatment in certain cases. He reported that: in general, upper airway surgery has a positive effect on arterial hypertension, markers of cardiovascular disease, insomnia, daytime symptoms and quality of life [34].

\subsubsection{Uvulopalatopharyngoplasty (UPPP)}

In this procedure there is an excision for the excess tissue from free margin of soft palate. Sometimes it is performed with tracheotomy (Figure 6). The response following this procedure is variable (approximately 50\%) [4].

\subsubsection{Continuous Positive Airway Pressure}

This method was developed in the early 1900s and re-discovered and made portable for domiciliary use in the 1980s. This method found to be effective in managing moderate to severe Obstructive Sleep Apnea cases [33]. and for the treatment for children whose Obstructive Sleep Apnea symptoms are not relieved after the performance of adenotonsillectomy [2].

Continuous positive airway pressure remains the most successful nonsurgical treatment and is still considered 


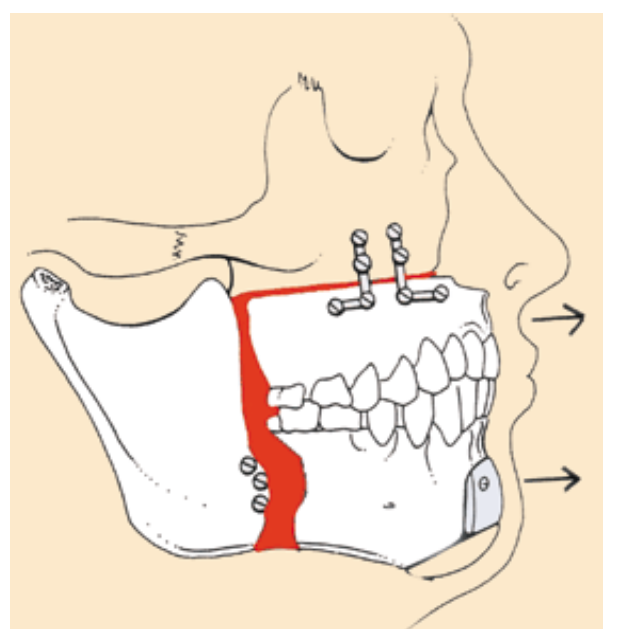

Figure 5. Maxillo-mandibular advancement surgery [33].

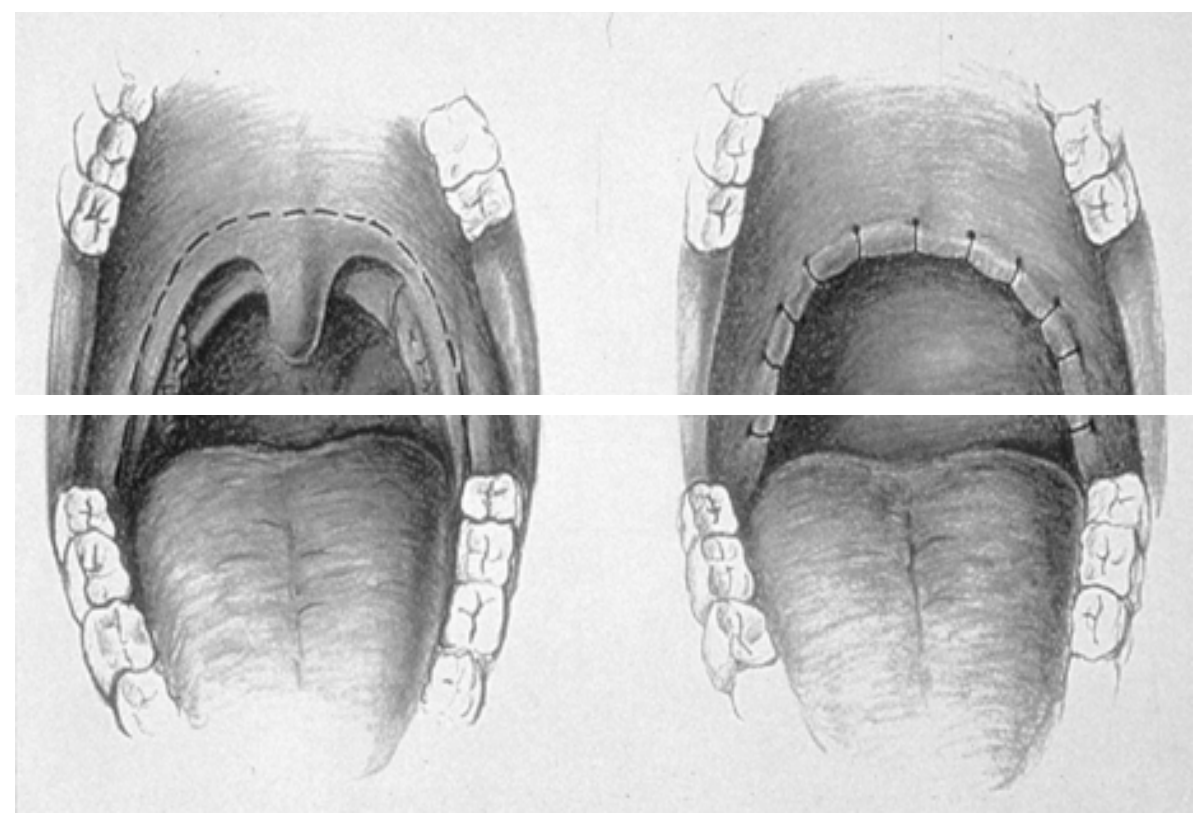

Figure 6. Uvulopalatopharyngoplasty procedure [4].

to be the "gold standard" treatment for obstructive sleep apnea patients [2] [36].

Sullivan and colleagues (1981) reported on the use of nasal continuous positive airway pressure (CPAP) for the treatment of OSA [37] (Figure 7).

This treatment involves wearing a mask overnight that exerts pressure on the upper airway to prevent airway collapse during sleep time [2].

The success of this method is dependent on the patient's compliance of wearing the mask [14]. Roughly 20 to 30 percent of patients experience problems while using continuous positive airway pressure and the device is ineffective if it is not used regularly [14].

The most commonly mentioned reasons for continuous positive airway pressure intolerance include: nasal dryness, facial ulcerations at the mask interface and claustrophobia [14].

It is advisable that patients have their pump checked by a Continuous positive Airway Pressure distributor or sleep centre at least once per year in order to avoid any complication such as pump breakdown as well as mask and tubing decay [35].

A recent study by Rishi et al. found a significant decrease in Body Mass Index in patients compliant with 


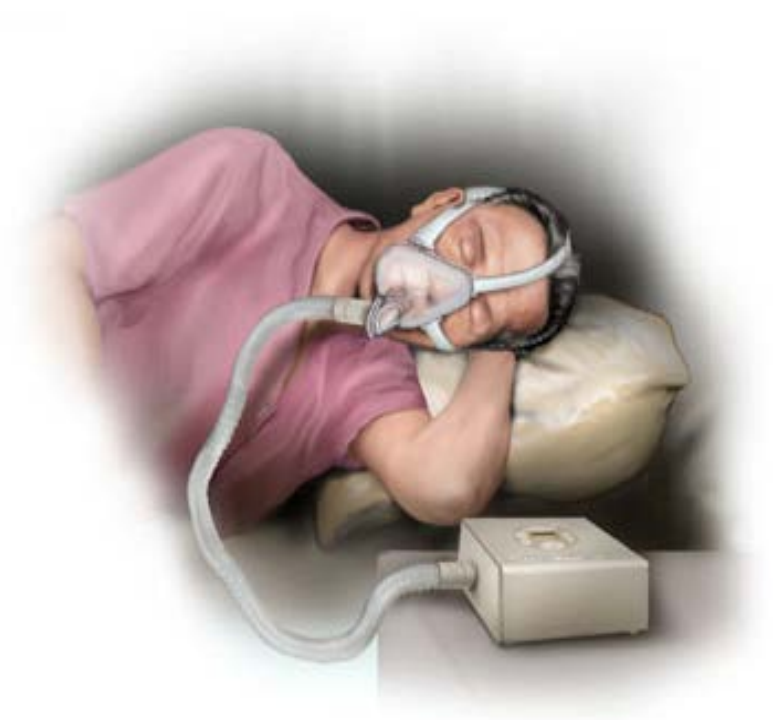

Figure 7. Continuous positive airway pressure [37]. (Internet, Google images, CPAP first page).

PAP therapy compared with noncompliant patients $(-1.2 \pm 0.7$ vs. $0.3 \pm 0.9 \mathrm{~kg} / \mathrm{m}, \mathrm{P} \leq 0.001)$. So this therapy may cause significant loss of weight within three months in obese patients with OSAS which improves treatment results [38].

\subsubsection{Oral Appliances}

The use of oral appliances has involved dentists in the treatment of Obstructive Sleep Apnea among both adults and children [2].

In the last few years, the use of oral appliances (provided primarily by dentist) for the treatment of Obstructive Sleep Apnea have become increasingly popular [39].

Currently, over 40 different types of oral appliances are available to specially trained dentists to treat OSA syndrome [40].

Oral appliances used in the treatment of obstructive sleep apnea can be allocated into three groups based on their mode of action: soft palate lifters (no longer in use today), tongue retaining devices and mandibular advancement appliances [41].

The main indication for the use of oral appliances in obstructive sleep apnea cases is a case in which the patient chooses to have neither surgery nor continuous positive airway pressure [2].

The most commonly used oral appliance nowadays is the mandibular advancement appliance that holds the mandible in a forward direction minimizing the upper airway collapse during sleep (Figure 8) [41].

The tongue retaining devices are used rarely. The indication for using such appliances is the presence of dental reasons preventing the construction of mandibular advancement appliance.

Mandibular advancement appliance can be either fixed (the protrusion distance is constant) or variable (the protrusion distance can be increased or decreased) [41].

1) The mechanism of action of oral appliances

It is well known that airway narrowing or even a complete occlusion is a normal Physiological event that occurs during sleep. In patients with sleep apnea, this normal response is exaggerated. So a combination of abnormal anatomy and physiology is necessary to produce pathological repetitive narrowing (or complete occlusion) of upper airway during sleep (sleep apnea).

Advancing the mandible forward can enlarge the airway and reduce pharyngeal collapsibility in patients with sleep apnea [41].

2) Efficiency of oral appliances

Oral appliances provide effective treatment for many patients with obstructive sleep apnea, in one study, they were effective in as many as $50 \%$ of patients with obstructive sleep apnea [35]. 


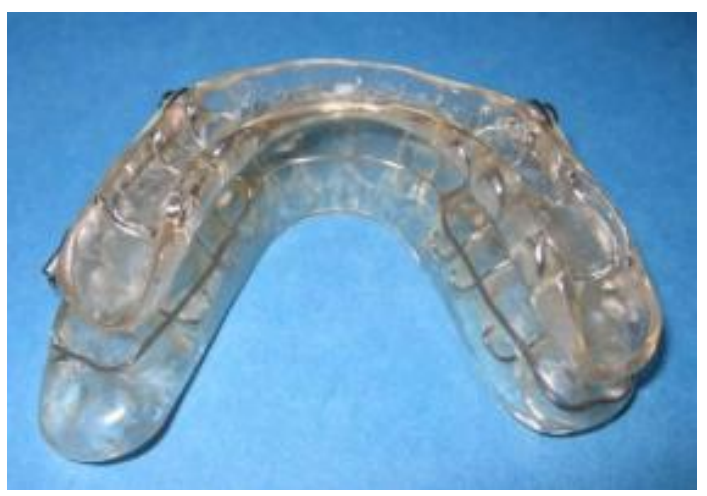

Figure 8. Mandibular advancement appliance [41].

Kushida C.A. et al. (2006) had reported that mandibular advancement appliances were capable of reducing snoring and mild to moderate Obstructive Sleep Apnea in about 30\% to 54\% of patients [36]. All investigations confirmed the effect of oral appliances on upper airway properties.

The efficacy (objective and subjective) of the oral appliance is very much dependent on the type of appliance and the degree of advancement. There is no "best" appliance. The best one is that which is comfortable to the patient and achieves the desired efficacy [41], so although a multitude of oral appliances are available, not all patients will find the same appliance effective [42].

According to Cozza and colleagues (2004), a new orthodontic appliance, a modified monobloc, is not only effective in reducing apnic events during sleep, but also improves subjective sleep quality and daytime performance among children with obstructive sleep apnea [43] [44].

Researchers investigating the use of oral appliances for children have found certain types to be particularly effective in treating OSA. For example In order to document the effectiveness of the used oral appliance, the patient should undergo a nocturnal polysomnographic test with the appliance in place [45].

Teixeira et al. (2013) proved the effectiveness of the mandibular advancement oral appliances in mild and moderate OSA cases but with various individual responses to this therapy [46].

3) Oral appliances versus other treatments

Schmidt-Nowara et al. (1991) compared between oral appliances and uvulopalatopharyngoplasty. The results demonstrated the superiority of oral appliances. At one year follow-up, sleep apnea was resolved $(\mathrm{AHI}<10)$ in $78 \%$ of the oral appliances group and $51 \%$ of the UPPP group. With longer follow-up, this success rate deteriorated [47].

A recent small case series of four patients (out of 43 treated with oral appliances) who elected maxilla-mandibular advancement surgery showed that initial AHI $=50$ dropped to 12 with oral appliance and to 2 after surgery [48].

The evidence available at present indicates that oral appliances successfully "cure" mild-to-moderate sleep apnea in $40 \%-50 \%$ of patients, and significantly improve it in additional $10 \%-20 \%$.

It should be noticed that these appliance can reduce but not totally eliminate the problem of snoring.

So based on the above data it is clear that the effectiveness of oral appliances in treating obstructive sleep apnea is inferior to Continuous Positive Airway Pressure. But similar to the effectiveness of the surgical procedures (although these surgical procedures are invasive and irreversible in comparison with oral appliances) [41].

4) Effect of oral appliances on daytime function

After 1995, the majority of investigations employed the Epworth sleepiness score (ESS). The results generally show improvement in daytime symptoms with oral appliances.

Engleman et al. (2002) carried out a very extensive study of daytime function comparing the effect of oral appliance to Continuous Positive Airway Pressure. Functional assessment included maintenance of wakefulness test, measures of daytime sleepiness and symptoms, measures of well-being (using the SF-36 questionnaire, HADS anxiety and depression score), and cognitive performance. The results favored Continuous Positive Airway Pressure in 7 out of 21 variables (including the ESS, AHI, effectiveness and symptoms), and showed no difference between Continuous Positive Airway Pressure and oral appliance in other variables (including the maintenance of wakefulness tests, cognitive performance and treatment preference) [49]. 
Walker-Engstrom et al. (2000) compared the quality of life in two parallel groups of patients with sleep apnea 1 year after treatment with either oral appliance or uvulopalatopharyngoplasty. There was other extensive assessment of three quality of life dimensions (vitality, contentment and sleep). Both groups improved compared to the baseline. There was no difference in vitality and sleep dimensions between the two groups, but the uvulopalatopharyngoplasty group was more content than the oral appliance group [50].

The conclusion from all of the investigations taken as a group must be that oral appliances improve daytime function, although they are not necessarily superior or consistently preferred than other treatments such as continuous positive airway pressure and uvulopalatopharyngoplasty (Table 3).

5) Effect of oral appliances on vascular disease

Numerous investigations examined the relationship between sleep apnea and vascular events, such as coronary artery disease, hypertension, and cerebro-vascular disease.

A study carried out by Gotsopoulos et al. (2004). They made this study in order to evaluate the effect of 4 weeks treatment with a mandibular advancement splint on 24-hour blood pressure in a sample consisted of 67 patients suffering from obstructive sleep apnea (mean Apnea Hypopnea Index = 27). The results revealed approximately $3.5 \mathrm{mmHg}$ drop in the systolic and diastolic blood pressure with treatment, but only during wakefulness. There was no change in blood pressure during sleep [51].

Another study by Barnes et al. (2004) compared the effect of 3 months treatment with oral appliance to Continuous Positive Airway Pressure and placebo (a tablet). The sample consisted of 110 patients with sleep apnea (mean AHI = 21), the 24 hour blood pressure was measured. Treatment with oral appliance (but not with CPAP or placebo tablet) resulted in the significant reduction in nighttime diastolic blood pressure by $2.2 \mathrm{mmHg}$. There were no changes in diastolic blood pressure during wakefulness and no changes in systolic blood pressure either during wakefulness or sleep [52].

A third study made by Yoshida (2006) who measured blood pressure in 161 patients with sleep apnea before and after 60 days of treatment with oral appliance. The results revealed a statistically significant reduction in blood pressure from 132.0/82.1 to 127.5/79.2 mmHg [53] (Table 4).

6) Side effects of oral appliances

Side effects caused by oral appliances are common, but they are relatively minor [41].

The most common side effects reported by patients are: Excessive salivation, mouth discomfort, and teeth discomfort. Other side effects recorded by patients include: difficulty in chewing, dry mouth, tongue discomfort, jaw discomfort, gum discomfort, headache, occlusal changes, temporomandibular pain, masseter muscle pain.

Based on the results of most studies, when oral appliances are properly constructed by a dentist expert in this

\begin{tabular}{cc}
\hline Table 3. Effect of oral appliance on daytime function. \\
\hline Researcher & Effect of oral appliance on daytime function \\
\hline $\begin{array}{c}\text { Engleman } \text { et al. (2002) } \\
\text { Walker-Engstrom et al. } \\
\text { (2000) }\end{array}$ & $\begin{array}{c}\text { No difference in vitality and sleep dimensions } \\
\text { between the oral appliance group and } \\
\text { uvulopalatopharyngoplasty group. }\end{array}$ \\
\hline Table 4. Effect of oral appliance on cardiovascular disease. \\
\hline Researcher \\
$\begin{array}{c}\text { Effect of oral appliances on vascular disease } \\
\text { Gotsopoulos et al. (2004) }\end{array}$ \\
$\begin{array}{c}3.5 \text { mmHg drop in the systolic and diastolic blood } \\
\text { pressure with oral appliance treatment, but only } \\
\text { during wakefulness. There was no change } \\
\text { in blood pressure during sleep. }\end{array}$ \\
Barnes et al. (2004) \\
$\begin{array}{c}\text { Significant reduction in nighttime diastolic blood pressure } \\
\text { by 2.2 mmHg. There were no changes in diastolic blood } \\
\text { pressure during wakefulness and no changes in systolic } \\
\text { blood pressure either during wakefulness or sleep. } \\
\text { Significant reduction in blood pressure from } \\
132.0 / 82.1 \text { to 127.5/79.2 mmHg. }\end{array}$ \\
\hline
\end{tabular}


field, the resulting oral appliances will be relatively comfortable in the majority of patients.

It is clear that dental-skeletal effects of oral appliances are certainly present, but the long term results and their clinical significance are unknown at this time. Further research is needed in this field.

7) Occlusal side effects caused by a mandibular advancement appliance in patients with obstructive sleep apnea

It has been found that the effects of oral appliances on the dentition are usually represented by a reduction in the overjet and the overbite [41].

Mandibular Advancement Appliances usually result in a labial movement of the lower incisors and a lingual tipping of the upper incisors resulting in a reduction of the overjet. In addition to their effect on the anterior teeth, these appliances usually produce, a lateral open bite since no eruption occurs in the premolars and molar area [54].

It should be known that Mandibular advancement appliances may in rare cases produce severe dental malocclusion. From here it is of great importance to follow up all patients being treated with such appliances in order to detect and treat any developing malocclusion [36].

8) Compliance

Compliance with oral appliances depends mainly on the balance between the perception of benefit and side effects. The assessment of compliance is a complex issue; because the perception of benefit is generally that of the bed partner, whereas the side effects are experienced by the wearer of the appliance.

The results of various studies regarding the compliance with wearing the oral appliances varies widely, and they Range from little (as 4\%) to high (as 76\%) at the end of 1 year.

The largest study regarding compliance is done by de Almeida et al. (2005). Who depended in his study on a mail survey of 544 patients, of whom 251 returned the questionnaire on the average of almost 6 years after the construction of the appliance. The majority of patients were fitted with Mandibular advancement appliance. At the time of follow-up, 161 patients continued to use the appliance. Assuming "the worst case scenario" (i.e. all those who did not return the questionnaire were no longer using the appliance) the compliance rate is $161 / 544=$ $30 \%$, while in the "best case scenario" the compliance rate is $161 / 251=64 \%$. Among those who used the appliance, $82 \%$ of bed partners were satisfied with this treatment; even among the non-users of appliances, $46 \%$ of bed partners were satisfied. The main reasons for discontinuing the use of the appliance were discomfort (44\%) and perception of little or no benefit (34\%) [55].

\subsubsection{Diet and Pharmacotherapy}

For obese children, weight loss and maintaining a healthy diet might prove to be the ultimate treatment for their OSA [2].

Anandam A. et al. (2013) evaluated the literature regarding the role of dietary weight loss in managing obstructive sleep apnea among obese patients. They found that these dietary weight loss programs are effective in reducing the severity of obstructive sleep apnea but not enough in relieving all respiratory events. So these weight reduction programs must be considered as an adjunct rather than curative therapy for obstructive sleep apnea patients [56].

Antibiotic medication has been used as a short-term treatment for snoring and obstruction, particularly when these problems are not persistent [2].

\subsubsection{Nasal Treatment}

Bury and Singh (2015) highlighted that nasal surgery for obstructive sleep apnea patients increase the quality of life and treatment compliance in some affected patients [57].

Few studies have demonstrated limited effectiveness and low tolerability of nasopharyngeal airway stenting devices, while others have shown a beneficial role in managing obstructive sleep apnea, with high acceptance among treated patients. In the short term, nasal trumpets have been successful in reducing airway obstruction [58].

Role of dentists in diagnosis of sleep apnea in children:

The dentist has a role in identifying children with adeno-tonsillar hypertrophy, then to refer them to a sleep clinic [2].

Once dentists identify children with adeno-tonsillar hypertrophy, they should inform the parents about the risk of OSA and further inform their family physician about the importance of sleep assessment in children with en- 
larged tonsils [2].

Children with Down syndrome are mainly predisposed to Obstructive Sleep Apnea, mainly because of their unique facial and upper-airway features which include midfacial and mandibular hypoplasia, an abnormally small hypo pharynx that encroaches on the tonsils and adenoids, and generalized pharyngeal muscle hypotonia with collapse of the upper airway during sleep. Oral cavity is smaller because of a low and narrow palate and underdevelopment of the midface. So, the diagnosis and treatment of sleep-disordered breathing in these patients reinforces the important role of the dentists in recognizing cases with obstructive sleep apnea [59].

Sleep abnormalities in children with Down syndrome are usually not cured via surgical procedures. In addition these patients may not tolerate continuous positive airway pressure treatment, but they should benefit from the use of oral appliances [59].

\section{Conclusions}

Obstructive sleep apnea (OSA) remains a life threatening disorder that should be diagnosed and managed in order to prevent the negative consequences on affected individuals.

The performance of an overnight polysomnographic test at specialized sleep clinics remains the gold standard for diagnosing obstructive sleep apnea disorder.

Obstructive sleep apnea is a condition that can be managed via surgical or non surgical methods. Continuous positive airway pressure represents the first line of treatment for most patients with obstructive sleep apnea. For up to $80 \%$ of children diagnosed with OSA, management via adenotonsillectomy was found to be an effective treatment.

The use of oral appliances has involved dentists in the treatment of Obstructive Sleep Apnea among both adults and children. The most commonly used oral appliance nowadays is the mandibular advancement appliance that holds the mandible in a forward direction minimizing the upper airway collapse during sleep so improving the sleep pattern in affected patients.

\section{References}

[1] Johal, A., Battagel, J.M. and Kotecha, B.T. (2005) Sleep Nasendoscopy: A Diagnostic Tool for Predicting Treatment Success with Mandibular Advancement Splints in Obstructive Sleep Apnea. European Journal of Orthodontics, 27, 607-614. http://dx.doi.org/10.1093/ejo/cji063

[2] Capua, M., Ahmadi, N. and Shapiro, C. (2009) Overview of Obstructive Sleep Apnea in Children: Exploring the Role of Dentists in Diagnosis and Treatment. Journal of the Canadian Dental Association, 75, 285-289.

[3] Wildhaber, J.H. and Moeller, A. (2007) Sleep and Respiration in Children: Time to Wake up! Swiss Medical Weekly, 137, 689-694.

[4] Rosen, C.L., Larkin, E.K., Kirchner, H.L., Emancipator, J.L., Bivins, S.F., Surovec, S.A., et al. (2003) Prevalence and Risk Factors for Sleep-Disordered Breathing in 8- to 11-Year-Old Children: Association with Race and Prematurity. Journal of Pediatric, 142, 383-389. http://dx.doi.org/10.1067/mpd.2003.28

[5] Johnson, E.O. and Roth, T. (2006) An Epidemiologic Study of Sleep-Disordered Breathing Symptoms among Adolescents. Sleep, 29, 1135-1142.

[6] Young, T., Palta, M., Dempsey, J., Skatrud, J., Weber, S. and Badr, S. (1993) The Occurrence of Sleep Disordered Breathing among Middle Aged Adults. The New England Journal of Medicine, 328, 1230-1235. http://dx.doi.org/10.1056/NEJM199304293281704

[7] Stradling, J.R. and Crosby, J.H. (1991) Predictors and Prevalence of Obstructive Sleep Apnea and Snoring in 1001 Middle Aged Men. Thorax, 46, 85-90. http://dx.doi.org/10.1136/thx.46.2.85

[8] Bondemark, L. and Lindman, R. (2000) Craniomandibular Status and Function in Patients with Habitual Snoring and Obstructive Sleep Apnea after Nocturnal Treatment with a Mandibular Advancement Splint: A 2-Year Follow-Up. European Journal of Orthodontics, 22, 53-60. http://dx.doi.org/10.1093/ejo/22.1.53

[9] Ye, L., Pien, G.W. and Weaver, T.E. (2009) Gender Differences in the Clinical Manifestation of Obstructive Sleep Apnea. SleepMed, 10, 1075-1084. http://dx.doi.org/10.1016/j.sleep.2009.02.006

[10] Duran, J., Esnaola, S., Rubio, R. and Iztueta, A. (2001) Obstructive Sleep Apnea-Hypopnea and Related Clinical Features in a Population-Based Sample of Subjects Aged 30 - 70 yr. American Journal of Respiratory and Critical Care Medicine, 163, 685-689. http://dx.doi.org/10.1164/ajrccm.163.3.2005065

[11] Battagel, J.M., Johal, A. and Kotecha, B. (2000) A Cephalometric Comparison of Patients with Snoring and Obstruc- 
tive Sleep Apnea. European Journal of Orthodontics, 22, 353-365. http://dx.doi.org/10.1093/ejo/22.4.353

[12] Ryan, C.M. and Bradley, T.D. (2005) Pathogenesis of Obstructive Sleep Apnea. Journal of Applied Physiology, 99, 2440-2450.

[13] Flemons, W.W., Buysse, D., Redline, S., et al. (1999) Sleep-Related Breathing Disorders in Adults: Recommendations for Syndrome Definition and Measurement Techniques in Clinical Research-The Report of an American Academy of Sleep Medicine Task Force. Sleep, 22, 667-689.

[14] Magliocca, K.R. and Helman, J.I. (2005) Obstructive Sleep Apnea: Diagnosis, Medical Management and Dental Implications. Journal of the American Dental Association, 136, 1121-1129.

[15] Qian, W., Tang, J., Jiang, G. and Zhao, L. (2015) Pharyngeal Wall Floppiness: A Novel Technique to Detect Upper Airway Collapsibility in Patients with OSAS. Otolaryngology_Head and Neck Surgery, 152, 759-764. http://dx.doi.org/10.1177/0194599814562728

[16] Weaver, J.M. (2014) Increased Anesthetic Risk for Patients with Obesity and Obstructive Sleep Apnea. Anesthesia Progress, 51, 75.

[17] Malhotra, A. and White, D.P. (2002) Obstructive Sleep Apnoea. The Lancet, 360, 237-245. http://dx.doi.org/10.1016/S0140-6736(02)09464-3

[18] Peppard, P.E., Young, T., Palta, M., Dempsey, J. and Skatrud, J. (2000) Longitudinal Study of Moderate Weight Change and Sleep-Disordered Breathing. The Journal of American Medical Association, 284, 3015-3021. http://dx.doi.org/10.1001/jama.284.23.3015

[19] Tangugsorn, V., Skatvedt, O., Krogstad, O. and Lyberg, T. (1995) Obstructive Sleep Apnoea: A Cephalometric Study. Part I. Cervico-Craniofacial Skeletal Morphology. European Journal of Orthodontics, 17, 45-56. http://dx.doi.org/10.1093/ejo/17.1.45

[20] Enache, A.M., Nimigean, V.R., Mihălţan, F., Didilescu, A.C., Munteanu, I. and Nimigean, V. (2010) Assessment of Sagittal and Vertical Skeletal Patterns in Romanian Patients with Obstructive Sleep Apnea. Romanian Journal of Morphology and Embryology, 51, 505-508.

[21] Dotan, Y., Pillar, G., Schwartz, A.R. and Oliven, A. (1985) Asynchrony of Lingual Muscle Recruitment during Sleep in Obstructive Sleep Apnea. Journal of Applied Physiology, 118, 1516-1524.

[22] Guilleminault, C., Connolly, S.J. and Winkle, R.A. (1983) Cardiac Arrhythmia and Conduction Disturbances during Sleep in 400 Patients with Sleep Apnea Syndrome. American Journal of Cardiology, 52, 490-494. http://dx.doi.org/10.1016/0002-9149(83)90013-9

[23] Morgan, B.J., Dempsey, J.A., Pegelow, D.F., Jacques, A., Finn, L., Palta, M., et al. (1998) Blood Pressure Perturbations Caused by Subclinical Sleep-Disordered Breathing. Sleep, 21, 737-746.

[24] McCrillisa, J.M., Haskell, J.A., Haskell, B.S., Brammer, M., Chenin, D., Scarfe, W.C. and Farman, A.G. (2009) Obstructive Sleep Apnea and the Use of Cone Beam Computed Tomography in Airway Imaging: A Review. Seminars in Orthodontics, 5, 63-69.

[25] Ciccone, M.M., Scicchitano, P., Zito, A., Cortese, F., Boninfante, B., Falcone, V.A., Quaranta, V.N., Ventura, V.A., Zucano, A., Di Serio, F., Damiani, M.F. and Resta, O. (2014) Correlation between Inflammatory Markers of Atherosclerosis and Carotid Intima-Media Thickness in Obstructive Sleep Apnea. Molecules, 19, 1651-1662. http://dx.doi.org/10.3390/molecules19021651

[26] Chan, J., Edman, J.C. and Koltai, P.J. (2004) Obstructive Sleep Apnea in Children. American Family Physician, 69, 1147-1154.

[27] Beebe, D.W. (2006) Neurobehavioral Morbidity Associated with Disordered Breathing during Sleep in Children: A Comprehensive Review. Sleep, 29, 1115-1134.

[28] Gottlieb, D.J., Vezina, R.M., Chase, C., Lesko, S.M., Heeren, T.C., Weese-Mayer, D.E., et al. (2004) Symptoms of Sleep-Disordered Breathing in 5-Year Old. The Journal of Pediatric, 145, 458-464. http://dx.doi.org/10.1016/j.jpeds.2004.05.039

[29] Suen, J.S., Arnold, J.E. and Brooks, L.J. (1995) Adenotonsillectomy for Treatment of Obstructive Sleep Apnea in Children. Archives of Otolaryngology-Head and Neck Surgery, 121, 525-530. http://dx.doi.org/10.1001/archotol.1995.01890050023005

[30] Elsherif, I. and Kareemullah, C. (1999) Tonsil and Adenoid Surgery for Upper Airway Obstruction in Children. Ear, Nose, and Throat Journal, 78, 617-620.

[31] Tarasiuk, A., Simon, T., Tal, A. and Reuveni, H. (2004) Adenotonsillectomy in Children with Obstructive Sleep Apnea Syndrome Reduces Health Care Utilization. Pediatrics, 113, 351-356. http://dx.doi.org/10.1542/peds.113.2.351

[32] Peltomki, T. (2007) The Effect of Mode of Breathing on Craniofacial Growth—Revisited. European Journal of Orthodontics, 29, 426-429. http://dx.doi.org/10.1093/ejo/cjm055 
[33] Vicini, C., Dallan, I., Campanini, A., De Vito, A., Barbanti, F., Giorgiomarrano, G., Bosi, M., Plazzi, G., Provini, F. and Lugaresi, E. (2010) Surgery vs. Ventilation in Adult Severe Obstructive Sleep Apnea Syndrome. American Journal of Otolaryngology — Head and Neck Medicine and Surgery, 31, 14-20. http://dx.doi.org/10.1016/j.amjoto.2008.09.002.

[34] Maurer, J.T. (2010) Surgical Treatment of Obstructive Sleep Apnea: Standard and Emerging Techniques. Current Opinion in Pulmonary Medicine, 16, 552-558. http://dx.doi.org/10.1097/MCP.0b013e32833ef7ea

[35] Kee, K. and Naughton, M.T. (2009) Sleep Apnoea-A General Practice Approach. Australian Family Physician, 38, 284-288.

[36] Hugentobler, M. and Scolozzi, P. (2010) Severe Dental Malocclusion: A Rare and Insidious Complication of Mandibular Advancement Devices for Obstructive Sleep Apnea Syndrome Treatment. Oral Surgery, Oral Medicine, Oral Pathology, Oral Radiology and Endodontics, 109, e28-e32. http://dx.doi.org/10.1016/j.tripleo.2009.10.040

[37] Sullivan, C.E., Issa, F.G., Berthon-Jones, M. and Eves, L. (1981) Reversal of Obstructive Sleep Apnoea by Continuous Positive Airway Pressure Applied through the Nares. The Lancet, 317, 862-865. http://dx.doi.org/10.1016/S0140-6736(81)92140-1

[38] Rishi, M.A., Copur, A.S., Nadeem, R. and Fulambarker, A. (2015) Effect of Positive Airway Pressure Therapy on Body Mass Index in Obese Patients with Obstructive Sleep Apnea Syndrome: A Prospective Study. American Journal of Therapeutics, in Press. http://dx.doi.org/10.1097/MJT.0000000000000072

[39] Bian, H. (2004) Knowledge, Opinions, and Clinical Experience of General Practice Dentists toward Obstructive Sleep Apnea and Oral Appliances. Sleep Breath, 8, 85-90. http://dx.doi.org/10.1055/s-2004-829633

[40] Wu, J.H., Hsu, C.Y., Wang, C.H., Lee, H.E., Lan, T.H. and Du, J.K. (2010) The Difference between Two Oral Appliances in Treating Obstructive Sleep Apnea: A Case Report. Journal of the Formosan Medical Association, 109, 163166. http://dx.doi.org/10.1016/S0929-6646(10)60037-X

[41] Hoffstein, V. (2007) Review of Oral Appliances for Treatment of Sleep-Disordered Breathing. Sleep Breath, 11, 1-22. http://dx.doi.org/10.1007/s11325-006-0084-8

[42] Veis, R.W. (1998) Snoring and Obstructive Sleep Apnea from a Dental Perspective. Journal of the California Dental Association, 26, 557-565.

[43] Cozza, P., Gatto, R., Ballanti, F. and Prete, L. (2004) Management of Obstructive Sleep Apnoea in Children with Modified Monobloc Appliances. European Journal of Pediatric Dentistry, 5, 24-29.

[44] Cozza, P., Polimeni, A. and Ballanti, F. (2004) A Modified Monobloc for the Treatment of Obstructive Sleep Apnoea in Paediatric Patients. European Journal of Orthodontics, 26, 523-530. http://dx.doi.org/10.1093/ejo/26.5.523

[45] Hoekema, A., Stegenga, B. and De Bont, L.G. (2004) Efficacy and Co-Morbidity of Oral Appliances in the Treatment of Obstructive Sleep Apneahypopnea: A Systematic Review. Critical Reviews in Oral Biology and Medicine, 15, 137155. http://dx.doi.org/10.1177/154411130401500303

[46] de Britto Teixeira, A.O., Abi-Ramia, L.B.P. and Almeida, M.A. (2013) Treatment of Obstructive Sleep Apnea with Oral Appliances. Progress in Orthodontics, 14, 10. http://dx.doi.org/10.1186/2196-1042-14-10

[47] Schmidt-Nowara, W.W., Meade, T.E. and Hays, M.B. (1991) Treatment of Snoring and Obstructive Sleep Apnea with Dental Orthosis. Chest, 99, 1378-1385. http://dx.doi.org/10.1378/chest.99.6.1378

[48] Knudson, R.C. and Meyer, J.B. (1993) Managing Obstructive Sleep Apnea. Journal of American Dental Association, 124, 75-78.

[49] Engleman,, H.M., McDonald, J.P., Graham, D., Lello, G.E., Kingshott, R.N., Coleman, E.L., Mackay, T.W. and Douglas, N.J. (2002) Randomized Crossover Trial of Two Treatments for Sleep Apnea/Hypopnea Syndrome: Continuous Positive Pressure and Mandibular Reposition Splint. American Journal of Respiratory and Critical Care Medicine, 166, 855-859.

[50] Walker-Engström, M.L., Wilhelmsson, B., Tegelberg, Å., Dimenäs, E. and Ringqvist, I. (2000) Quality of Life Assessment of Treatment with Dental Appliance or UPPP in Patients with Mild to Moderate Obstructive Sleep Apnea: A Prospective Randomized 1-Year Follow-Up Study. Journal of Sleep Research, 9, 303-308.

[51] Gotsopoulos, H., Kelly, J.J. and Cistulli, P.A. (2004) Oral Appliance Therapy Reduces Blood Pressure in Obstructive Sleep Apnea: A Randomized, Controlled Trial. Sleep, 27, 934-941.

[52] Barnes, M., McEvoy, R.D., Banks, S., Tarquinio, N., Murray, C.G., Vowles, N. and Pierce, R.J. (2004) Efficacy of Positive Airway Pressure and Oral Appliance in Mild to Moderate Obstructive Sleep Apnea. American Journal of Respiratory and Critical Care Medicine, 170, 656-664.

[53] Yoshida, K. (2006) Effect on Blood Pressure of Oral Appliance Therapy for Sleep Apnea Syndrome. International Journal of Prosthodontics, 19, 61-66.

[54] Rose, E.C., Schnegelsberg, C., Staats, R. and Jonas, I.E. (2001) Occlusal Side Effects Caused by a Mandibular Ad- 
vancement Appliance in Patients with Obstructive Sleep Apnea. Angle Orthodontist, 71, 452-460.

[55] De Almeida, F.R., Lowe, A.A., Tsuiki, S., Otsuka, R., Wong, M., Fastlicht, S. and Ryan, C.F. (2006) Long Term Compliance and Side Effects of Oral Appliances Used for the Treatment of Snoring and Obstructive Sleep Apnea Syndrome. Journal of Clinical Sleep Medicine, 1, 143-152.

[56] Anandam, A., Akinnusi, M., Kufel, T., Porhomayon, J. and El-Solh, A.A. (2013) Effects of Dietary Weight Loss on Obstructive Sleep Apnea: A Meta-Analysis. Sleep Breath, 17, 227-234. http://dx.doi.org/10.1007/s11325-012-0677-3

[57] Bury, S.B. and Singh, A. (2015) The Role of Nasal Treatments in Snoring and Obstructive Sleep Apnoea. Current Opinion in Otolaryngology Head and Neck Surgery, 23, 39-46. http://dx.doi.org/10.1097/moo.0000000000000129

[58] Kumar, A.R., Guilleminault, C., Certal, V., Li, D., Capasso, R. and Camacho, M. (2014) Nasopharyngeal Airway Stenting Devices for Obstructive Sleep Apnoea: A Systematic Review and Meta-Analysis. The Journal of Laryngology Otology, 29, 1-9.

[59] Waldman, H.B., Hasan, F.M. and Perlman, S. (2009) Down Syndrome and Sleep-Disordered Breathing: The Dentist’s Role. Journal of American Dental Association, 140, 307-312. http://dx.doi.org/10.14219/jada.archive.2009.0159 